\title{
Bicarbonate Secretion In Vivo by Rat Distal Tubules during Alkalosis Induced by Dietary Chloride Restriction and Alkali Loading
}

\author{
David Z. Levine, Michelle lacovitti, and Virginia Harrison \\ With statistical analyses by Rama Nair and David Vandorpe \\ Departments of Medicine and Physiology, University of Ottawa and Ottawa General Hospital, Ottawa, Ontario K1H 8 M5 Canada
}

\begin{abstract}
To examine in vivo the separate effects on distal tubule $\mathrm{JtCO}_{2}$, of dietary chloride restriction, bicarbonate loading, and changes in luminal chloride concentration, we microperfused distal tubules at a physiologic flow rate $(8 \mathrm{nl} / \mathrm{min})$ with solutions containing either 45 or $0 \mathrm{mM}$ chloride (after gluconate substitution). Rats were fed a diet containing zero, minimal, or normal amounts of chloride, while drinking either water or a solution of $0.15 \mathrm{M}$ sodium bicarbonate. Neither extracellular fluid volume contraction nor negative chloride balance ensued. Analysis of covariance with repeated measures demonstrated that dietary chloride, drinking sodium bicarbonate, and perfusion with either $45 \mathrm{mM}$ or zero chloride, each have separate and significant modulating effects on distal tubule bicarbonate secretion. During mild alkalemia, there is modest bicarbonate secretion which is significantly different from zero $(-9.9 \pm 3.2$ $\mathrm{pmol} \cdot \mathrm{min}^{-1} \cdot \mathrm{mm}^{-1}, P<0.01$, and which is suppressed after perfusion with zero chloride. In contrast, during more pronounced metabolic alkalosis after supplemental bicarbonate drinking, the bicarbonate secretory flux is brisk $(-26 \pm 3$ $\left.\mathrm{pmol} \cdot \mathrm{min}^{-1} \cdot \mathrm{mm}^{-1}\right)$ and significantly different from zero and persists $\left(-11 \pm 3 \mathrm{pmol} \cdot \mathrm{min}^{-1} \cdot \mathrm{mm}^{-1}\right)$ even during perfusion with zero luminal chloride. Accordingly, in this two-day model of alkalosis induced by dietary chloride restriction, there is regulatory secretion of bicarbonate by distal tubules in vivo which is modulated by luminal chloride concentration. (J. Clin. Invest. 1991. 87:1513-1518.) Key words: acid-base • kidney • renal micropuncture $\bullet$ alkalemia
\end{abstract}

\section{Introduction}

We have recently reported that net bicarbonate secretion ${ }^{1}$ can occur in rat distal tubules in vivo and this response is modulated by changes in luminal chloride concentration (1). Because we found B-type intercalated cells in rat surface distal

Portions of this work have appeared in abstract form (1990. Clin. Invest. Med. 13:470).

Received for publication 24 September 1990 and in revised form 10 December 1990.

1. Throughout this paper, unless otherwise stated, the term "secretion of bicarbonate" refers to absolute net bicarbonate accumulation in the tubular lumen which is determined by the sum of opposing unidirectional secretory and reabsorptive fluxes. The unidirectional secretory flux may involve apical $\mathrm{Cl} / \mathrm{HCO}_{3}$ exchange, passive paracellular entry of bicarbonate, or other mechanisms.

J. Clin. Invest.

(c) The American Society for Clinical Investigation, Inc.

0021-9738/91/05/1513/06 \$2.00

Volume 87, May 1991, 1513-1518 tubules (2) and these are presumed to have an apical $\mathrm{HCO}_{3} / \mathrm{Cl}$ exchanger, our findings are broadly consistent with numerous in vitro studies which have defined the bicarbonate secretory characteristics of the exchanger in rabbit cortical collecting tubules (3). However, insofar as the bicarbonate secretory flux was observed in association with the alkalosis after administration of pharmacologic doses of desoxycorticosterone acetate, and at high perfusion rates, it is uncertain whether secretion would occur in metabolic alkalosis associated with dietary chloride restriction and under conditions when distal tubular flow rate and fluid composition reflect the free-flow state. Indeed, two free-flow studies which assessed distal tubule bicarbonate flux in chloride depleted alkalotic rats indicate that this segment reabsorbs rather than secretes bicarbonate $(4,5)$.

It is obvious that these considerations have profound implications for acid-base regulation by distal nephron segments capable of both reabsorbing and secreting bicarbonate. Continued bicarbonate reabsorption in the face of severe alkalemia indicates that the distal tubule plays a "nonhomeostatic" role in chronic metabolic alkalosis, contributing to the maintenance of the disturbance. In contrast, if distal tubules can be shown to secrete bicarbonate under physiologic conditions, this response would be regulatory insofar as the severity of the alkalemia should be mitigated.

Another area of controversy concerns the function of the distal tubule during the repair of chloride depletion metabolic alkalosis by provision of chloride and to what extent luminal chloride concentrations modulate net bicarbonate flux. Wesson (6) has reported that during chloride correction, distal tubule chloride reabsorption is increased presumably with a concomitant reduction in bicarbonate reabsorption. In contrast, Galla et al. (7) could detect no change in the rate of either chloride or bicarbonate reabsorption in rats with maintained or correcting alkalosis.

In the studies referred to above, bicarbonate fluxes were measured under different experimental conditions which might account for differing results. Variables include the duration of the alkalosis, net balances of chloride and potassium, supplemental alkali feeding, distal tubule bicarbonate load, the degree of extracellular fluid (ECF) ${ }^{2}$ volume depletion, and whether or not animals are fasted before the experiment. The present studies were undertaken to determine in fed rats the separate effects on distal tubule bicarbonate flux of short term dietary chloride restriction, drinking $0.15 \mathrm{M} \mathrm{NaHCO}_{3}$, and changes in luminal chloride concentrations. To control the effects of changes in bicarbonate load and tubular flow rate, we microperfused distal tubules at physiologic flow rates $(8 \mathrm{nl} /$ $\mathrm{min}$ ) with solutions containing either 45 or $0 \mathrm{mMCl}$, but with a composition similar to early distal tubular fluid in other respects. Rats were fed a diet containing zero, minimal, or nor-

2. Abbreviation used in this paper: ECF, extracellular fluid. 
mal amounts of chloride for two days, with or without drinking a bicarbonate solution. This resulted in neither significant ECF volume depletion nor negative chloride balances. In this way we studied the mild alkalemia associated with selective dietary chloride restriction as well as the more severe alkalemia associated with both chloride restriction and bicarbonate loading.

Our results indicate that dietary chloride restriction, alkali drinking, and luminal chloride concentration each have separate and significant effects on distal tubule bicarbonate secretion in vivo. In mildly alkalotic rats, bicarbonate is secreted into the $45 \mathrm{mM} \mathrm{Cl}$ perfusate, but is arrested with a zero $\mathrm{Cl}$ perfusate. In the more alkalotic rats, the bicarbonate secretory flux is striking and persists to a significant degree even with zero $\mathrm{Cl}$ perfusion.

\section{Methods}

Experimental design and statistical methods (Fig. 1). These studies were undertaken to assess the influences on distal tubule $\mathrm{JtCO}_{2}$ of three factors: selective dietary chloride depletion, alkali loading, and changes in luminal chloride concentration. This assessment was made under microperfusion conditions so as to avoid variations in flow or load of bicarbonate during paired perfusions. At the same time, we ensured that perfusion flow rate and composition reflected free-flow conditions. We studied separately distal tubule $\mathrm{JtCO}_{2}$ in mildly alkalemic rats after short-term ingestion of a zero chloride diet (8) and in more severely alkalotic rats after drinking bicarbonate. The effects of these maneuvers could be assessed by comparison with other animals ingesting a normal chloride diet. Accordingly, as shown in Fig. 1, three groups of rats were first studied while drinking water and eating a diet either free of chloride, containing minimal chloride, or containing normal amounts of chloride. In each case, we documented ingestion of the diet by measuring the amount of food eaten and weight gained, and by demonstrating that urine chloride excretion reflected intake. To assess the separate effects of alkali loading, comparisons were made with animals drinking water, as well as with animals eating a zero or normal chloride diet. In each of these five groups of animals the influence of

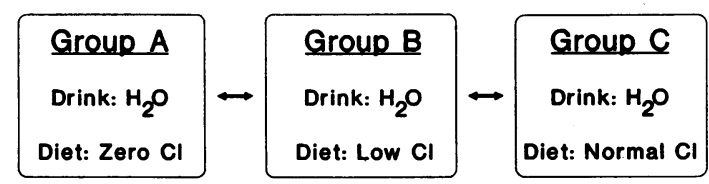

Analysis of Covariance With Repeated Measures

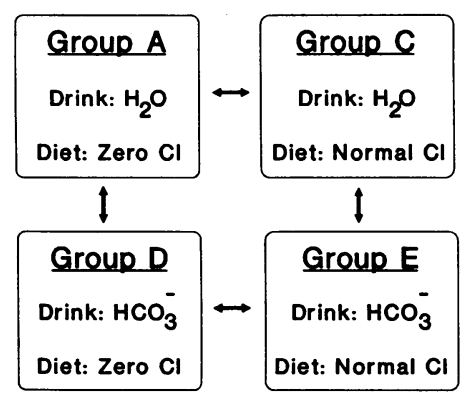

Two-Way Analysis of Covariance With Repeated Measures

Figure 1. Experimental design. See also Methods and Results for details of the statistical approach. changing the luminal chloride concentration of the perfusate was also studied.

The statistical analyses employed must reflect the intent of the experimental design, namely, to identify factors that independently influence distal tubule $\mathrm{JtCO}_{2}$ while quantifying the effect of confounding variables. One-way and two-way analysis of covariance with repeated measures were used to assess the separate effects of dietary chloride, alkali loading, and luminal chloride on distal tubule $\mathrm{JtCO}_{2}$ (Fig. 1), while controlling for the effects of concomitant changes in flow rate, bicarbonate load, $J_{\mathrm{v}}$ and $J_{\mathrm{C}}$. Thus, comparisons between groups were based on adjusted means of $\mathrm{JtCO}_{2} . F$ statistics were computed to test for equality of adjusted means in accordance with standard statistical practices, and the resulting probabilities are stated throughout the text and in Table I. The repeated measures design in the ANCOVA analysis took into account that paired collections were taken from each tubule perfused (i.e., perfusion with a $45 \mathrm{mM} \mathrm{Cl}$ solution and then a $0 \mathrm{mM} \mathrm{Cl}$ solution, or vice versa). Differences between means shown in Table I were tested for statistical significance by $t$ test, adjusted for multiple comparisons using Bonferroni probabilities.

Rats and diets (Table II). These studies were performed on fed male Sprague-Dawley rats weighing $\sim 300 \mathrm{~g}$, bred and raised in a climate controlled facility at the University of Ottawa. Rats were divided into five experimental groups. Group A rats ate a chloride-free diet and drank distilled water for a period of $2 \mathrm{~d}$. The diet contained, in grams per kilogram diet: $\mathrm{Na}_{2} \mathrm{CO}_{3} 1.15, \mathrm{~K}_{2} \mathrm{CO}_{3} 1.74, \mathrm{~K}_{2} \mathrm{SO}_{4} 1.81$, $\mathrm{MgCO}_{3} \cdot \mathrm{Mg}(\mathrm{OH})_{2} \cdot 5 \mathrm{H}_{2} \mathrm{O}$ 1.59, Basal Teklad Diet Powder 993.7. This diet provided the National Research Council-recommended amounts of sodium, potassium, magnesium, and sulphate levels without producing nephrocalcinosis $(9,10)$. Group B rats were fed a minimal chloride diet and drank distilled water for $2 \mathrm{~d}$. This diet was prepared by adding $0.82 \mathrm{~g} \mathrm{NaCl}$ to each kilogram of chloride-free diet. Group C rats ate a normal chloride diet $(14.0 \mathrm{~g} \mathrm{NaCl} / \mathrm{kg})$ and drank distilled water for $2 \mathrm{~d}$, resulting in urinary chloride excretion rates comparable with those of normal chow-fed rats from this laboratory $(1,8)$. Group $D$ rats ate the chloride-free diet and drank a $0.15 \mathrm{M} \mathrm{NaHCO}_{3}$ solution for $2 \mathrm{~d}$, whereas group $\mathrm{E}$ rats ate the normal chloride diet and also drank the $\mathrm{NaHCO}_{3}$ solution for $2 \mathrm{~d}$. Animals were housed in individual metabolic cages that permitted urine collections, under oil with thymol as a preservative, for $16 \mathrm{~h}$ before the microperfusion experiment. They had free access to food and drink until the time of the experiments.

Microperfusion experiments. Rats were anesthetized with $100 \mathrm{mg} /$ kg Inactin (BYK Gulden, Konstanz, FRG) and were prepared for micropuncture as previously described (1). All animals were infused with $1.0 \%$ body weight of donor plasma followed by $1 \% \mathrm{~b} . \mathrm{w}$./ $\mathrm{h}$ of a solution containing $92 \mathrm{mM} \mathrm{Cl}, 30 \mathrm{mM} \mathrm{HCO}_{3}, 120 \mathrm{mM} \mathrm{Na}$, and $2 \mathrm{mM} \mathrm{K}$ for groups $A$ and $D$, with few exceptions, or with $1 \%$ b.w./h of isotonic saline for groups B, C, and E. The data derived from paired microperfusion collections, from six additional unpaired collections (group A) and from free-flow collections. 43 pairs of distal tubular collections were obtained from 37 rats. The perfusion solutions contained (in millimolar): $55 \mathrm{Na}, 2 \mathrm{~K}, 12 \mathrm{HCO}_{3}, 26 \mathrm{urea}$, and $45 \mathrm{Cl}$ or gluconate for chloride substitution. The sequence of perfusion with chloride-containing or chloride-free perfusates was varied. In addition, 24 free-flow early distal samples were obtained often, but not always, from the rats providing the paired data. These samples confirmed that total $\mathrm{CO}_{2}$ and chloride concentrations of 12 and $45 \mathrm{mM}$, respectively, and a flow rate of 8 $\mathrm{nl} / \mathrm{min}$ reasonably reflected free-flow conditions. All perfusion solutions contained $0.05 \%$ FD\&C green dye and were gassed with humidified $9 \% \mathrm{CO}_{2} / 91 \% \mathrm{O}_{2}$ to attain a pCO $\mathrm{pC}_{2}$ of $65 \mathrm{~mm} \mathrm{Hg}$. All in vivo collections were quantitative and timed, and the concentration of $\left[{ }^{3} \mathrm{H}\right]$ inulin was determined in the perfusate and in the samples to detect significant departures from the nominal perfusion rates. In the present experiments the in vivo perfusion rate was $7.8 \pm 0.1 \mathrm{nl} / \mathrm{min}$ for the 86 paired collections.

Analytical methods and calculations. Total carbon dioxide concentration was measured by microcalorimetry as previously described (1). Particular care was taken to avoid loss of dissolved carbon dioxide. 
Table I. Blood and Balance Data

\begin{tabular}{|c|c|c|c|c|c|}
\hline & Group A & Group B & Group C & Group D & Group E \\
\hline Diet & Zero Cl & Low $\mathrm{Cl}$ & Normal Cl & Zero Cl & Normal Cl \\
\hline Drinking Solution & $\mathrm{H}_{2} \mathrm{O}$ & $\mathrm{H}_{2} \mathrm{O}$ & $\mathrm{H}_{2} \mathrm{O}$ & $\mathrm{NaHCO}_{3}$ & $\mathrm{NaHCO}_{3}$ \\
\hline No. of rats & 9 & 9 & 6 & 11 & 9 \\
\hline Body weight ( $g$ ) (overnight) & $9 \pm 1$ & $11 \pm 2$ & $11 \pm 1$ & $8 \pm 1^{*}$ & $15 \pm 1$ \\
\hline Food consumed $(g)$ & $22 \pm 1$ & $23 \pm 1$ & $24 \pm 1$ & $22 \pm 1$ & $25 \pm 1$ \\
\hline \multicolumn{6}{|l|}{ Blood data } \\
\hline $\mathrm{pH}$ & $7.42 \pm 0.01$ & $7.39 \pm 0.01$ & $7.41 \pm 0.01$ & $7.52 \pm 0.03^{*}$ & $7.44 \pm 0.01$ \\
\hline $\mathrm{pCO}_{2}(\mathrm{mmHg})$ & $51.3 \pm 1.7$ & $53.4 \pm 1.3$ & $45.7 \pm 1.7$ & $47.6 \pm 2.7$ & $48.4 \pm 2.1$ \\
\hline $\mathrm{HCO}_{3}(m E q /$ liter $)$ & $32.1 \pm 0.5^{\ddagger}$ & $31.3 \pm 0.5^{\ddagger}$ & $27.8 \pm 0.2^{*}$ & $37.3 \pm 1.2^{\ddagger 5}$ & $31.6 \pm 1.0$ \\
\hline $\mathrm{Na}(m E q /$ liter $)$ & $145 \pm 1$ & $142 \pm 1$ & $144 \pm 2$ & $143 \pm 1$ & $145 \pm 1$ \\
\hline $\mathrm{K}(m E q /$ liter $)$ & $4.5 \pm 0.1$ & $4.6 \pm 0.1$ & $4.1 \pm 0.2$ & $3.3 \pm 0.1^{\ddagger}$ & $3.8 \pm 0.1$ \\
\hline $\mathrm{Cl}$ (mEq/liter) & $98 \pm 0$ & $100 \pm 1$ & $100 \pm 1$ & $89 \pm 2^{\ddagger 5}$ & $98 \pm 1$ \\
\hline Het $(\%)$ & $47.1 \pm 0.7^{*}$ & $46.9 \pm 0.8$ & $44.1 \pm 1.2$ & $44.6 \pm 0.7$ & $43.4 \pm 0.8$ \\
\hline Prot $(m g / d l)$ & $6.4 \pm 0.1^{*}$ & $6.5 \pm 0.2$ & $5.8 \pm 0.2$ & $5.7 \pm 0.1$ & $5.8 \pm 0.2$ \\
\hline \multicolumn{6}{|l|}{ Urine data } \\
\hline Volume $(\mathrm{ml} / 16 \mathrm{~h})$ & $22 \pm 2$ & $15 \pm 2^{*}$ & $18 \pm 2$ & $53 \pm 8^{\prime \prime}$ & $37 \pm 5$ \\
\hline $\mathrm{pH}$ & $5.99 \pm 0.05^{5}$ & $5.93 \pm 0.07^{8}$ & $6.09 \pm 0.04$ & $7.71 \pm 0.11^{\ddagger}$ & $7.87 \pm 0.5^{\ddagger}$ \\
\hline $\mathrm{HCO}_{3}(\mu E q / 16 h)$ & $23 \pm 6^{8}$ & $13 \pm 3^{5}$ & $30 \pm 6^{8}$ & $4350 \pm 795^{\ddagger}$ & $3241 \pm 602^{\ddagger}$ \\
\hline $\mathrm{Na}(\mu E q / 16 h)$ & $331 \pm 42^{\text {에 }}$ & $649 \pm 113^{\text {snl }}$ & $5375 \pm 597^{8}$ & $8862 \pm 1342$ & $9935 \pm 739$ \\
\hline $\mathrm{K}(\mu E q / 16 h)$ & $396 \pm 42$ & $580 \pm 121$ & $591 \pm 93$ & $1236 \pm 161^{5}$ & $234 \pm 42$ \\
\hline $\mathrm{Cl}(\mu E q / 16 h)$ & $30 \pm 11^{\ddagger \S}$ & $259 \pm 52^{ \pm 5}$ & $3615 \pm 257$ & $275 \pm 64^{8}$ & $3654 \pm 396$ \\
\hline
\end{tabular}

* $P<0.05$ compared with group E. ${ }^{\ddagger} P<0.01$ compared with group $C .{ }^{8} P<0.01$ compared with group E. " $P<0.05$ compared with group C.

Micropuncture pipettes and sample handling pipettes contained Hepes-buffered mineral oil and samples were placed on a quartz dish flooded with Hepes-buffered mineral oil. A separate tray contained four $\mathrm{NaHCO}_{3}$ standards $(5,10,20,30 \mathrm{mM} \mathrm{NaHCO} 3)$ in water-equilibrated mineral oil. A standard curve was run before sample analysis and standards bracketed the determination of the sample and perfusate $\mathrm{tCO}_{2}$ concentrations.

Tubular fluid chloride concentrations were determined by constant current electrotitration with potentiometric end-point sensing according to a modified method of Ramsey et al. (11). A series of $\mathrm{NaCl}$ standards was run before and during sample and perfusate analysis to generate a regression line and assess instrument stability. For low chloride concentrations, a midcurve chloride standard was added to the sample or perfusate before titration.

Other methods and calculations have been recently detailed (1).

\section{Results}

Whole animal data (Table I)

Rats drinking water (groups $A-C$ ). These rats ate a diet containing no chloride, minimal chloride, or normal amounts of chloride while drinking water. All animals gained $\sim 6-8 \mathrm{~g}$ body weight during the night before the experiment and consumed $\sim 20 \mathrm{~g}$ of food. Plasma bicarbonate concentration in group $\mathrm{C}$ was not different than that previously reported by us in normally fed rats, while group A rats eating a zero chloride diet had a modest elevation of plasma bicarbonate. Plasma potassium concentration was similar in all three groups. Neither significant ECF volume depletion or negative chloride balances were present. There were no significant changes in body weight nor

Table II. Experimental Protocols

\begin{tabular}{|c|c|c|}
\hline & Diet & Infusion \\
\hline $\begin{array}{r}\text { Group } A \\
\text { (8 rats) }\end{array}$ & $2 \mathrm{~d}$, zero $\mathrm{Cl}$ diet, drinking water & $\begin{array}{l}1 \% \text { b.w. donor plasma followed by } 1 \% \text { b.w./h infusion composed of } 92 \mathrm{mM} \mathrm{Cl} \text {, } \\
30 \mathrm{mM} \mathrm{HCO}, 120 \mathrm{mM} \mathrm{Na} \text {, and } 2 \mathrm{mM} \mathrm{K}\end{array}$ \\
\hline $\begin{array}{r}\text { Group B } \\
\text { (9 rats) }\end{array}$ & $2 \mathrm{~d}$, low $\mathrm{Cl}$ diet, drinking water & $1 \%$ b.w. donor plasma followed by $1 \%$ b.w./h of isotonic saline \\
\hline $\begin{array}{r}\text { Group C } \\
\text { (6 rats) }\end{array}$ & $2 \mathrm{~d}$, normal $\mathrm{Cl}$ diet, drinking water & $1 \%$ b.w. donor plasma followed by $1 \%$ b.w./h of isotonic saline \\
\hline $\begin{array}{r}\text { Group D } \\
\text { (7 rats) }\end{array}$ & $\begin{array}{l}2 \mathrm{~d} \text {, zero } \mathrm{Cl} \text { diet, drinking } 0.15 \mathrm{M} \\
\mathrm{NaHCO}_{3}\end{array}$ & $\begin{array}{l}1 \% \text { b.w. donor plasma followed by } 1 \% \text { b.w./h infusion composed of } 92 \mathrm{mM} \mathrm{Cl} \text {, } \\
30 \mathrm{mM} \mathrm{HCO}, 120 \mathrm{mM} \mathrm{Na} \text {, and } 2 \mathrm{mM} \mathrm{K}\end{array}$ \\
\hline $\begin{array}{r}\text { Group E } \\
\text { (7 rats) }\end{array}$ & $\begin{array}{l}2 \mathrm{~d} \text {, normal Cl diet, drinking } 0.15 \mathrm{M} \\
\mathrm{NaHCO}_{3}\end{array}$ & $1 \%$ b.w. donor plasma followed by $1 \%$ b.w./h of isotonic saline \\
\hline
\end{tabular}




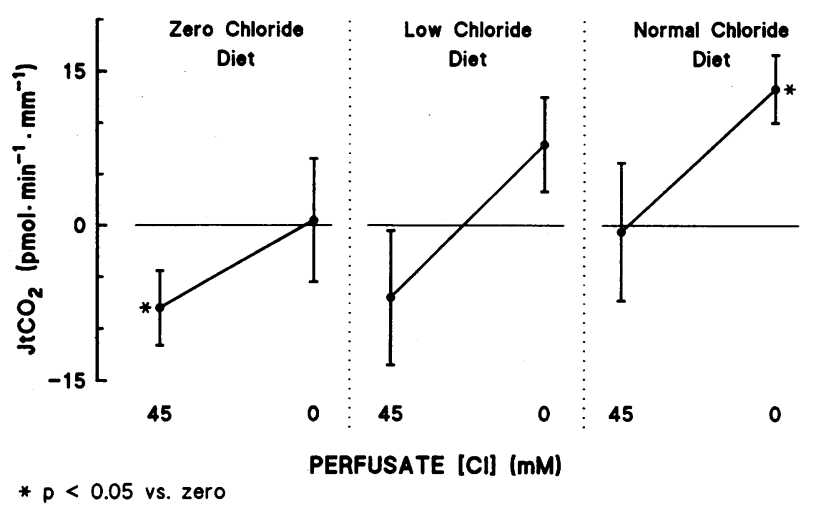

Figure 2. Distal tubule $\mathrm{JtCO}_{2}$ in rats drinking water on different chloride-containing diets. See also Results and Table III.

urine chloride excretion reflected dietary intake being extremely low in group A (some urines contained only zero or 1 $\mathrm{mEq} \mathrm{Cl}$ concentration), and in the normal range $(3.5 \mathrm{mEq} / 16$ hours) in Group C.

Rats drinking $\mathrm{NaHCO}_{3}$ (Groups $\mathrm{D}, \mathrm{E}$ ). Group D rats, which drank $\mathrm{NaHCO}_{3}$ and ate the zero chloride diet, were frankly alkalotic and excreted an alkaline urine without significant ECF volume depletion or negative chloride balances. Although urine chloride excretion rates were minimal, there was a difference of $\sim 7 \mathrm{~g}$ in overnight weight gain when compared with group $\mathrm{E}$ rats. Because hematocrit and plasma protein concentrations were not different from group $\mathrm{E}$ rats, we believe significant ECF volume contraction could not have been present during this 2-d period. Plasma potassium concentration was 3.3 $\mathrm{mM}$, a value significantly less than in group $\mathrm{A}(P<0.05)$. In contrast, group $\mathrm{E}$ rats, which ate the normal chloride diet, did not become alkalotic.

\section{Microperfusion data}

Rats drinking $\mathrm{H}_{2} \mathrm{O}$ (groups $\mathrm{A}-\mathrm{C}$ ). Fig. 2 and Table III summarize microperfusion data for rats perfused with zero or $45 \mathrm{mM}$ $\mathrm{Cl}$. The rate of total $\mathrm{CO}_{2}$ secretion with $45 \mathrm{mM} \mathrm{Cl}$ perfusate was modest and became less negative or significantly positive with zero $\mathrm{Cl}$ perfusate. These data were analyzed by the method of repeated measures analysis of covariance and revealed a significant effect of both diet $(P<0.05)$ and perfusate [Cl], $(P<0.05)$, on modulating $\mathrm{JtCO}_{2}$. As shown in Fig. 2, group $A$ rats eating the zero chloride diet had significant bicarbonate secretion $(P<0.05)$ using a one-tailed $t$ test when compared with zero. In view of the interest of this measurement and the borderline significance value, we added six data points where only the $45 \mathrm{mM}$ perfusate collection was successful. For these 14 samples $\left(-9.9 \pm 3.2 \mathrm{pmol} \cdot \mathrm{min}^{-1} \cdot \mathrm{mm}^{-1}\right)$, the difference from zero is significant at the $P<0.01$ level. In group $C$ rats, the positive reabsorptive flux seen with zero chloride perfusate was significantly different from zero $(P<0.01)$.

Table III also gives data on water movements and chloride fluxes, which showed marked and consistent changes when perfusate $[\mathrm{Cl}]$ was changed. In all tubules, perfusion with zero $\mathrm{Cl}$ was associated with a lower $J_{\mathrm{v}}$ and brisk chloride influx when compared to the higher rate of water reabsorption and net chloride reabsorption during $45 \mathrm{mM} \mathrm{Cl}$ perfusion. These measures, $J_{\mathrm{Cl}}$ and $J_{\mathrm{V}}$, were significant covariates among the three groups $(P<0.01)$ but neither load $\left(\dot{V} \times\right.$ perfusate $\left.\left[\mathrm{tCO}_{2}\right]\right)$ nor flow $(\dot{V})$, potential determinants of $\mathrm{JtCO}_{2}$, were significant covariates.

Rats drinking $\mathrm{NaHCO}_{3}$ (Table III, Fig. 3). Groups D and E provide data from rats eating a zero $\mathrm{Cl}$ diet or the chloride-containing diet and drinking $\mathrm{NaHCO}_{3}$. These groups should be compared with groups $\mathrm{A}$ and $\mathrm{C}$, as outlined in Methods and in Fig. 1. Despite the $8 \mathrm{nl} / \mathrm{min}$ perfusion rate, group $\mathrm{D}$ rats showed striking total $\mathrm{CO}_{2}$ secretion with $45 \mathrm{mMCl}$. The perfusate [total $\mathrm{CO}_{2}$ ] rose almost threefold, despite the lower plasma potassium concentration. Surprisingly, even with zero $\mathrm{Cl}$ perfusion, $\mathrm{JtCO}_{2}$ remained negative, albeit not to the same degree as with the $45 \mathrm{mM} \mathrm{Cl}$ perfusion. These data are in contrast to those from rats eating the chloride-containing diet where $\mathrm{JtCO}_{2}$ was not different from zero with both perfusates.

A two-way analysis of covariance with repeated measures was performed on groups A, C, D, and E as depicted in Fig. 1 . The analysis provides conclusions identical to those described for groups A-C, namely that both perfusate $\mathrm{Cl}$ and dietary $\mathrm{Cl}$

Table III. Summary of Microperfusion Data

\begin{tabular}{|c|c|c|c|c|c|c|c|c|c|c|}
\hline & $\begin{array}{l}\text { No. tubules/ } \\
\text { No. rats }\end{array}$ & $\begin{array}{l}\text { Tubular } \\
\text { length }\end{array}$ & $\begin{array}{l}\text { Perfusion } \\
\text { rate }\end{array}$ & $\begin{array}{l}\text { Perfusate } \\
\text { [Cl] }\end{array}$ & $\begin{array}{l}\text { Mean } \\
\text { luminal } \\
{[\mathrm{Cl}]}\end{array}$ & $\begin{array}{l}\text { Perfusate } \\
{\left[\mathrm{tCO}_{2}\right]}\end{array}$ & $\begin{array}{l}\text { Collected } \\
{\left[\mathrm{tCO}_{2}\right]}\end{array}$ & $J_{\mathrm{v}}$ & $J_{\mathbf{a}}$ & $\mathrm{JtCO}_{2}$ \\
\hline & & $m m$ & $n l / \min$ & $m M$ & $m M$ & $m M$ & $m M$ & $\mathrm{nl} \cdot \mathrm{min}^{-1} \cdot \mathrm{mm}^{-1}$ & $\mathrm{pmol} \cdot \mathrm{min}^{-1} \cdot \mathrm{mm}^{-1}$ & $\mathrm{pmol} \cdot \mathrm{min}^{-1} \cdot \mathrm{mm}^{-1}$ \\
\hline \multicolumn{11}{|l|}{ Group A } \\
\hline Drink: $\mathrm{H}_{2} \mathrm{O}$ & $8 / 8$ & $1.5 \pm 0.0$ & $8.0 \pm 0.2$ & $0 \pm 0$ & $15.8 \pm 2.6$ & $12.4 \pm 0.4$ & $19.0 \pm 1.2$ & $1.9 \pm 0.2$ & $-111 \pm 20$ & $1 \pm 6^{*}$ \\
\hline Diet: Zero Cl & & & $7.5 \pm 0.2$ & $44.3 \pm 0.2$ & $52.5 \pm 2.0$ & $12.1 \pm 0.5$ & $25.6 \pm 1.7$ & $2.3 \pm 0.1$ & $61 \pm 6$ & $-8 \pm 4^{*}$ \\
\hline \multicolumn{11}{|l|}{ Group B } \\
\hline Drink: $\mathrm{H}_{2} \mathrm{O}$ & 9/9 & $1.5 \pm 0.1$ & $7.6 \pm 0.2$ & $0 \pm 0$ & $20.8 \pm 4.1$ & $11.6 \pm 0.3$ & $15.0 \pm 0.5$ & $1.7 \pm 0.3$ & $-132 \pm 20$ & $8 \pm 5^{*}$ \\
\hline Diet: Low Cl & & & $7.9 \pm 0.2$ & $44.9 \pm 0.2$ & $55.2 \pm 1.9$ & $12.1 \pm 0.4$ & $22.6 \pm 1.2$ & $2.2 \pm 0.3$ & $35 \pm 9$ & $-7 \pm 7^{*}$ \\
\hline \multicolumn{11}{|l|}{ Group C } \\
\hline Drink: $\mathrm{H}_{2} \mathrm{O}$ & $9 / 6$ & $1.4 \pm 0.1$ & $7.7 \pm 0.2$ & $0.4 \pm 0.3$ & $15.1 \pm 2.3$ & $12.9 \pm 0.5$ & $16.3 \pm 1.0$ & $2.0 \pm 0.3$ & $-107 \pm 16$ & $13 \pm 4^{*}$ \\
\hline Diet: Normal Cl & & & $7.6 \pm 0.2$ & $46.2 \pm 0.7$ & $57.5 \pm 2.1$ & $12.6 \pm 0.4$ & $24.8 \pm 1.4$ & $2.6 \pm 0.4$ & $56 \pm 26$ & $-1 \pm 7^{*}$ \\
\hline \multicolumn{11}{|l|}{ Group D } \\
\hline Drink: $0.15 \mathrm{M} \mathrm{NaHCO}_{3}$ & 9/7 & $1.4 \pm 0.0$ & $8.1 \pm 0.3$ & $0.6 \pm 0.2$ & $11.8 \pm 0.8$ & $11.7 \pm 0.2$ & $21.9 \pm 1.2$ & $2.0 \pm 0.2$ & $-82 \pm 9$ & $-12 \pm 3^{*}$ \\
\hline Diet: Zero Cl & & & $7.9 \pm 0.4$ & $45.9 \pm 1.0$ & $48.5 \pm 2.5$ & $11.9 \pm 0.4$ & $34.5 \pm 3.9$ & $2.7 \pm 0.2$ & $125 \pm 13$ & $-26 \pm 3^{*}$ \\
\hline \multicolumn{11}{|l|}{ Group E } \\
\hline Drink: $0.15 \mathrm{M} \mathrm{NaHCO}_{3}$ & $8 / 7$ & $1.6 \pm 0.1$ & $8.0 \pm 0.2$ & $0 \pm 0$ & $12.3 \pm 1.0$ & $12.4 \pm 0.3$ & $18.4 \pm 1.2$ & $1.9 \pm 0.3$ & $-84 \pm 12$ & $4 \pm 6^{*}$ \\
\hline Diet: Normal Cl & & & $7.8 \pm 0.3$ & $44.8 \pm 0.2$ & $48.2 \pm 1.5$ & $12.8 \pm 0.2$ & $27.1 \pm 3.1$ & $2.4 \pm 0.4$ & $85 \pm 22$ & $0 \pm 7^{*}$ \\
\hline
\end{tabular}

* Statistical analyses, described in Methods and Results, reveal significant effects on distal tubule $\mathrm{JtCO}_{2}$ of dietary chloride restriction, bicarbonate loading, and perfusate chloride concentration. 
independently influence $\mathrm{JtCO}_{2}$. In addition, there is a significant effect of the bicarbonate-drinking solution as well $(P$ $<0.01$ ). Again, neither load nor flow rate influenced $\mathrm{JtCO}_{2}$, whereas both $J_{\mathrm{v}}$ and $J_{\mathrm{C}}$ were significant covariates. In group $\mathrm{E}$ animals, as shown in Fig. 3, the $\mathrm{JtCO}_{2}$ at $45 \mathrm{mM}$ and $0 \mathrm{mM} \mathrm{Cl}$ perfusion was not significantly different from zero $(P<0.01)$. It is noteworthy, that the reabsorptive flux in group $\mathrm{C}$ animals with zero $\mathrm{Cl}$ perfusate was also significantly different from zero $(P<0.01)$, suggesting a suppression of the reabsorptive flux by bicarbonate ingestion (see Discussion).

\section{Discussion}

The present studies were designed to examine the separate effects in vivo of dietary chloride restriction, ingestion of supplemental bicarbonate, and luminal chloride concentration on distal tubule bicarbonate transport $\left(\mathrm{JtCO}_{2}\right)$ in the rat. We used a model of metabolic alkalosis induced by dietary chloride restriction without ECF volume contraction or negative chloride balance. Our results demonstrate for the first time that $(a)$ dietary chloride restriction and drinking sodium bicarbonate independently modulate $\mathrm{JtCO}_{2},(b)$ intratubular perfusion with either $45 \mathrm{mM}$ or zero chloride significantly alters $\mathrm{JtCO}_{2}$ in both control and alkalotic rats, and (c) modest but significant net bicarbonate secretion occurs at normal flow during mild alkalosis, whereas when the alkalosis is more marked distal tubule bicarbonate secretion is brisk, thereby tending to mitigate rather than maintain the alkalotic state.

Comparison with free-flow studies. Wesson (4) has recently noted that conflicting data on segmental bicarbonate handling in metabolic alkalosis may derive from differences in the means of inducing the disturbance, the presence of potassium depletion, changes in tubular load of bicarbonate, and the duration of the disturbance before the measurement of bicarbonate flux. The studies of Wesson (4) and of De Mello Aires and Malnic (5) provide distal tubule data on bicarbonate transport during chloride depletion metabolic alkalosis of 1 or 4 wk duration. These rats received furosemide and supplemental bicarbonate and ate a chloride-free diet. At the time of study, they were potassium depleted and had been fasted overnight. In Wesson's study (4), puncture of late and early distal segments of the same tubule revealed increased rates of bicarbonate reab-

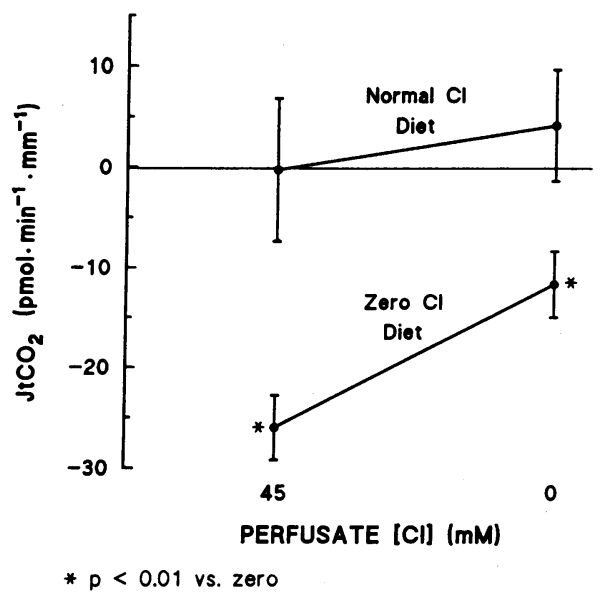

Figure 3. Distal tubule $\mathrm{JtCO}_{2}$ in rats drinking $0.15 \mathrm{M} \mathrm{NaHCO}_{3}$ on different chloride-containing diets. See also Results and Table III. sorption when compared with control animals. The load of bicarbonate delivered to the punctured tubules was increased in comparison to controls and contributed, at least in part, to the enhanced reabsorptive rate, with potassium depletion thought to also play a role (4). These valuable and difficult free-flow measurements follow the studies undertaken almost 20 years ago by De Mello Aires and Malnic (5). The means of inducing chloride depletion metabolic alkalosis was similar but at the time of the acute experiment a mannitol and bicarbonate diuresis was induced to facilitate sample collection, and significant hypokalemia (plasma $[\mathrm{K}]=2.55 \mathrm{mM}$ ) was also present (12). These authors also concluded that the distal tubule reabsorbed greater amounts of bicarbonate than under control conditions, although absolute reabsorptive rates were not directly measured for each tubule punctured.

\section{Factors influencing distal tubule $\mathrm{JtCO}$}

1. Feeding and fasting. The bicarbonate secretory fluxes in our studies were measured in rats fed before the experiments. We have already demonstrated that whether rats are fasted or not before the experiment can determine the direction of $\mathrm{JtCO}_{2}$ (13). It is possible, therefore, that the reabsorptive flux in fasted rats reported by Wesson (4) may be suppressed by feeding.

2. Tubular bicarbonate load. In our studies, bicarbonate load was rigidly controlled in our paired perfusions and documented not to be a significant covariate, whereas in the freeflow studies load was increased. It is well established that load can increase the bicarbonate reabsorptive flux in free-flow distal tubule studies as reported by Capasso et al. (14).

3. Potassium depletion. Potassium depletion was absent or minimal in our rats secreting bicarbonate but in the rats studied by De Mello Aires and Malnic and Wesson $(4,5)$, potassium depletion was present and could have stimulated distal tubule bicarbonate reabsorption as suggested by Capasso et al. (14). Presumably, if group D potassium concentrations were normal, the striking secretory flux we observed would have been even more pronounced.

4. ECF volume contraction and negative chloride balance. Excretion rates for chloride and hematocrit and plasma protein concentrations indicate the rats we studied were not ECF volume contracted nor in negative chloride balance. In chloride depletion associated with diuretic use or gastric alkalosis, it is possible that the attendant chloride losses and ECF volume depletion would stimulate bicarbonate reabsorption.

5. Duration of the metabolic alkalosis. Our experiments also differed markedly from these free-flow studies in that the alkalosis we induced was only of 2-d duration. It is possible that cell changes leading to enhanced proton secreting ATPase activity, or suppression of unidirectional bicarbonate secretory mechanisms (see below), might evolve over subsequent days or weeks. The persistence of bicarbonate reabsorption in distal tubules during the phase of rebound alkalosis that follows $\mathrm{NH}_{4} \mathrm{Cl}$ loading is an example of a response which is first regulatory during the acidotic phase, and then becomes nonregulatory in that it contributes to the maintenance of the metabolic alkalosis (15). In chloride depletion metabolic alkalosis, it is possible that distal tubules respond in a regulatory manner in the first $48 \mathrm{~h}$ and then change their $\mathrm{JtCO}_{2}$ from net secretion to reabsorption.

6. Histological variability. It is likely that our two-looped microperfusion technique requires a length of distal tubule sufficient to include the connecting segment and the initial col- 
lecting tubule where B-type intercalated cells are found (2). On the other hand, free-flow collections can be made proximal to the initial collecting tubule. Accordingly, the bicarbonate reabsorptive fluxes reported by Wesson (4) and De Mello Aires and Malnic (5) may reflect transport by portions of the distal tubule devoid of bicarbonate secreting cells.

7. Supplemental bicarbonate ingestion. As already noted, in our laboratory, overnight fasting before the acute micropuncture experiment determines whether the net bicarbonate flux is reabsorptive or secretory, but alkali loading has an additional effect (13). In bicarbonate-loaded rats studied by Wesson (16), $\mathrm{JtCO}_{2}$ fell from 25 to $11 \mathrm{pmol} \cdot \mathrm{min}^{-1} \cdot \mathrm{mm}^{-1}$ despite the fasted state of the animals. In our previous microperfusion studies we obtained similar results after bicarbonate loading in fasting rats. Indeed, even in the present investigations on fed animals, the reabsorptive flux in group $\mathrm{E}$ rats is lower than in group $\mathrm{C}$ rats after drinking bicarbonate. Similarly, the microperfusion data of Chan et al. (17) show a suppression of $\mathrm{JtCO}_{2}$ as a result of alkali loading in fed rats. Just as normal feeding may allow regulatory bicarbonate secretion to occur, bicarbonate loading may be thought to result in a regulatory suppression of $\mathrm{JtCO}_{2}$.

8. $J_{V}$ and $J_{C l} . J_{\mathrm{V}}$ and $J_{\mathrm{Cl}}$ are also potential modulators of $\mathrm{JtCO}_{2}$. In all cases, perfusates containing zero chloride showed highly significant $\mathrm{Cl}$ secretion and lower $J_{\mathrm{v}}$ when compared with chloride-containing perfusates. As already noted in $\mathrm{Re}-$ sults, these were significant covariates and were accounted for in the designation of significance of the three parameters of interest, i.e., dietary chloride, alkali ingestion, and luminal chloride concentration.

9. Luminal chloride concentration and transtubular bicarbonate concentration gradients. Because we measured only net bicarbonate fluxes in these studies, changes in net secretion might be the result of alterations in the unidirectional secretory flux (whether due to apical anion exchange or paracellular entry, etc.) or changes in the unidirectional reabsorptive flux. Accordingly, the interpretation of our results of perfusion with zero chloride should also include the possibility that the predominant effect is one of an increased reabsorptive flux.

What might account for the lower net bicarbonate secretory flux in the mildly alkalotic rats (group A), versus the threefold greater flux in the more severely alkalotic animals (group D)? In each case, chloride-free perfusion reduced the net secretory flux, but only in group A rats was it completely suppressed. The mean luminal chloride concentrations were comparable after zero chloride perfusion, and above the suggested $K_{\mathrm{m}}$ of 4-11 $\mathrm{mM}$ for the $\mathrm{HCO}_{3} / \mathrm{Cl}$ exchanger in the rabbit (3). In this in vivo setting, it is possible that the characteristics of the exchanger are altered by the alkalosis per se, dietary chloride restriction, or alkali loading. Moreover, our experimental variables may have also modulated other determinants of net bicarbonate transport. The transepithelial potential difference, the transepithelial diffusional permeability to bicarbonate, and the proton secretory rate may have varied in control and alkalotic animals in response to changes in lumen chloride concentration, transtubular bicarbonate concentration gradients, dietary chloride restriction, and alkali loading.

\section{Implications for maintenance of chloride depletion metabolic alkalosis}

Our short-term studies separated the effects of dietary chloride restriction from those of alkali loading in the absence of ECF volume contraction and negative chloride balance. Nevertheless, our data may be relevant to at least one facet of the clinical presentation of metabolic alkalosis associated with vomiting. In this situation, three observations have been consistently made. Within the first $36 \mathrm{~h}$ there is $(a)$ a sustained alkalemia, (b) excretion in the urine of negligible amounts of chloride, and (c) excretion in the urine of large amounts of bicarbonate (18). The provision of alkali in our group D rats would correspond to the generation of new bicarbonate by loss of gastric juice, and the bicarbonate secretory flux we observed could lead to the appearance of bicarbonate in the urine within the first $36 \mathrm{~h}$. This bicarbonaturia has been variably described as a disequilibrium state (18) or a state in which the "reabsorptive capacity for bicarbonate" is exceeded by distal nephron bicarbonate load. Our findings suggest this could represent a distal tubule and cortical collecting duct bicarbonate secretory flux.

\section{Acknowledgments}

We are grateful to Beth Caskie and Diane Gagnon for expert help in preparing the manuscript.

This work was supported by a grant from the Medical Research Council of Canada.

\section{References}

1. Levine, D. Z., D. Vandorpe, and M. Iacovitti. 1990. Luminal chloride modulates distal tubule bidirectional bicarbonate flux in vivo. J. Clin. Invest. 85:1793-1798.

2. Levine, D. Z. 1990. Single-nephron studies: implications for acid-base regulation. Kidney Int. 38:744-761.

3. Schuster, V. L. 1989. Physiology and cell biology update: control mechanisms for bicarbonate secretion. Am. J. Kidney Dis. 13:348-352.

4. Wesson, D. E. 1989. Augmented bicarbonate reabsorption by both the proximal and distal nephron maintains chloride-deplete metabolic alkalosis in rats. J. Clin. Invest. 84:1460-1469.

5. De Mello Aires, M., and G. Malnic. 1972. Micropuncture study of acidification during hypochloremic alkalosis in the rat. Pfluegers Arch. Eur. J. Physiol. 331:13-24.

6. Wesson, D. E. 1990. Depressed distal tubule acidification corrects chloridedepleted alkalosis in rats. Am. J. Physiol. 259:F636-F644.

7. Galla, J. H., D. N. Bonduris, and R. G. Luke. 1989. Superficial distal and deep nephrons in correction of metabolic alkalosis. Am. J. Physiol. 257:F107F113.

8. Levine, D. Z., D. Roy, G. Tolnai, L. Nash, and B. G. Shah. 1974. Chloride depletion and nephrocalcinosis. Am. J. Physiol. 227:878-883.

9. National Research Council. 1962. Nutrient requirements of domestic animals. Natl. Acad. Sci. Publ. 990:68.

10. Bernhart, F. W, and R. M. Tomerelli. 1966. A salt mixture supplying the National Research Council estimates of the mineral requirements of the rat. $J$. Nutr. 89:495-500.

11. Ramsay, J. A., R. H. J. Brown, and P. C. Croghan. 1955. Electronic titration of chloride in small volumes. J. Exp. Biol. 32:822-829.

12. De Mello Aires, M., and G. Malnic. 1972. Renal handling of sodium and potassium during hypochloremic alkalosis in the rat. Pfluegers Arch. Eur. J. Physiol. 331:215-225.

13. Levine, D. Z., M. Iacovitti, L. A. Nash, and D. Vandorpe. 1988. Secretion of bicarbonate by rat distal tubules in vivo. Modulation by overnight fasting. $J$. Clin. Invest. 81:1873-1878.

14. Capasso, G., P. Jaeger, G. Giebisch, V. Guckian, and G. Malnic. 1987. Renal bicarbonate reabsorption in the rat. II. Distal tubule load dependence and effect of hypokalemia. J. Clin. Invest. 80:409-414.

15. Vandorpe, D. H., and D. Z. Levine. 1990. Distal tubule bicarbonate reabsorption $\mathrm{JtCO}_{2}$ in vivo persists during rebound alkalosis. Kidney Int. 37:548. (Abstr.)

16. Wesson, D. E. 1990. Dietary bicarbonate reduces rat distal nephron acidification evaluated in situ. Am. J. Physiol. 258:F870-F876.

17. Chan, Y. L., G. Malnic, and G. Giebisch. 1989. Renal bicarbonate reabsorption in the rat. III. Distal tubule perfusion study of load dependence and bicarbonate permeability. J. Clin. Invest. 84:931-938.

18. Kassirer, J. P., and W. B. Schwartz. 1966. The response of normal man to selective depletion of hydrochloric acid. Factors in the genesis of persistent gastric alkalosis. Am. J. Med. 40:10-26. 